Research Article

\title{
Patient Level Delay in Diagnosis of Multi-Drug Resistant Tuberculosis among Patients Attending Tertiary Care Hospital in Haryana
}

\author{
$\underline{\text { RB Jain }}$, $\underline{\text { Rajesh Gupta }}^{2}$, Sandeep Sharma $^{3}$, Tarun Kumar $^{4}, \underline{\text { Ginni Agrawal }}^{5}$, Priyanka Choudhary $^{6}$, \\ Sarika Yadav ${ }^{7}$, Anand Jain ${ }^{8}$ \\ ${ }^{1}$ Senior Professor, Department of Community Medicine, Pt. B.D. Sharma PGIMS Rohtak, Rohtak, Haryana, India. \\ ${ }^{2}$ Professor, Department of Respiratory Medicine, Pt. B.D. Sharma PGIMS Rohtak, Rohtak, Haryana, India. \\ 3,4,5,7 Junior Resident, ${ }^{6}$ Senior Resident, Department of Community Medicine, Pt. B.D. Sharma PGIMS Rohtak, Rohtak, Haryana, \\ India. \\ ${ }^{8}$ Junior Resident, Department of Medicine, Teerthanker Mahaveer Medical Collage \& Research Centre, Moradabad, U.P., India. \\ DOI: https://doi.org/10.24321/2455.7048.201918
}

\section{I $\quad \mathbf{N} \quad \mathbf{F} \quad \mathbf{O}$}

\section{Corresponding Author:}

Sandeep Sharma, Department of Community Medicine, Pt. B.D. Sharma PGIMS Rohtak, Rohtak, Haryana, India.

E-mail Id:

sandeep4gkg@gmail.com

\section{Orcid Id:}

https://orcid.org/0000-0001-7683-4253

How to cite this article:

Jain RB, Gupta R, Sharma S, Kumar T, Agrawal $G$, Choudhary $P$ et al. Patient Level Delay in Diagnosis of Multi-Drug Resistant Tuberculosis among Patients Attending Tertiary Care Hospital in Haryana. Epidem Int 2019; 4(4): 8-15.

Date of Submission: 2019-12-10

Date of Acceptance: 2020-01-22

\section{$\begin{array}{llllllll}\mathbf{A} & \mathbf{B} & \mathbf{S} & \mathbf{T} & \mathbf{R} & \mathbf{A} & \mathbf{C} & \mathbf{T}\end{array}$}

Background: Multi-Drug Resistant Tuberculosis (MDR-TB) besides increasing cost and duration of treatment also increases the mortality and morbidity. Less awareness in the community and diagnostic constraints for MDR-TB at patient level is a major cause of delay in diagnosis.

Objective: To find out the delay in diagnosis of MDR-TB and factors affecting this delay among MDR-TB patients attending tertiary care hospital, PGIMS Rohtak, Haryana, India.

Material and Methods: It is a hospital based cross-sectional study carried out in the department of Respiratory Medicine, PGIMS Rohtak, Haryana from March 2018 to February 2019 among 125 admitted patients of MDR-TB in tertiary care hospital, PGIMS Rohtak. A pre-designed, pretested, semi-structured interview schedule was used and data were analysed using SPSS version 20.0 and Chi square test was applied.

Result: The mean and median patient delay was found to be 31.11 days and 21 days, respectively. Extent of patient delay was significantly associated with socio-demographic factors like age, sex, literacy status, occupation, addiction and past history of TB in patients.

Conclusion: In this study, it was concluded that there was significant delay in the diagnosis as well as seeking treatment at patient level which was associated with socio-demographic factors. Thus, there is urgent need to boost up the Information, Education and Communication (IEC) activities to increase awareness among general public about the importance of early diagnosis and treatment of MDR-TB.

Keywords: Patient Level Delay, MDR-TB, Tertiary Care Hospital 


\section{Introduction}

Tuberculosis (TB) is a contagious, airborne infection caused by Mycobacterium tuberculosis (Mtb). Globally $5 \%$ to $10 \%$ of people infected with Mtb develop the disease during their lifetime and estimated TB incidence in 2018 was 10 million (9-11 million). India accounted for $27 \%$ of global burden, that is, 2.69 million cases. Overall, about $90 \%$ of cases occur among adults, with proportionately more cases in men than women. The male: female ratio of pulmonary TB among adults is approximately $2: 1{ }^{1}$

In most cases, TB is treatable and curable; however, persons with TB may die if they do not get proper treatment. ${ }^{2}$ When the Mycobacterium causing TB is resistant to both the frontline anti-tubercular drugs (i.e., Rifampicin and Isoniazid), it is labelled as Multi-Drug-Resistant TB (MDR-TB). Of all TB patients, the incidence of MDR-TB is 3.4\% among new cases and $18 \%$ among previously treated cases. Globally in 2018, 484,000 people developed MDR/ RR-TB, out of which $50 \%$ cases were from three countries-India (27\%), China (14\%) and Russian Federation (9\%). ${ }^{1}$ Development of multi-drug resistance in TB makes management of TB even more difficult because of the reasons like poor cure rate $(56 \%)$, misdiagnosis of MDR-TB as nonresistant TB, longer duration of treatment and more side-effects. ${ }^{1}$ The first line anti-TB drugs are in use since the inception of TB Control Program and now the most probable cause for the increasing prevalence of MDR-TB is because of development of resistance to these drugs. This is evident from the fact that resistance to at least one anti-TB drug has been reported from all countries. ${ }^{3}$

Globally estimated incidence of MDR was 4,84,000 but out of these cases, only 1,86,772 were notified in 2018. Out of total notified cases, only 1,56,071 were enrolled for treatment which was $32 \%$ of total estimated incidence. This showed a huge gap between incidence and treatment initiation.

Closing this wide gap requires timely detection of TB casesand increasing the proportion of TB cases bacteriologically confirmed, coverage of testing for drug resistance among bacteriologically confirmed cases and coverage of treatment for those diagnosed with MDR/RR-TB. ${ }^{1}$

It has been observed that among the reasons for failure of control of tuberculosis, delay in diagnosis and timely initiation of MDR-TB treatment are most important factors, which also reflects quality of implementation of the program. Two important factors have been highlighted for this delay, one on the part of patients in reporting to health facility and second on the part of the health facility that even after reporting of the patient, detection of the disease and its management is considerably delayed. ${ }^{5}$
If delay in diagnosis and management is minimised, it will be helpful in decreasing the burden of MDR-TB cases and mortality associated with it without any extra input. So, the present study was planned to find out the extent of patient level delay in diagnosis of MDR-TB among patients attending tertiary care hospital, PGIMS Rohtak, and to study the factors affecting this delay in diagnosis of MDR-TB.

\section{Materials and Methods}

It was hospital based cross-sectional study carried out at DOTS plus site under Programmatic Management of Drug Resistant TB (PMDT) in the Department of Respiratory Medicine, PGIMS, Rohtak and Haryana, India.

The study was conducted for a period of one year from March 2018 to Feb 2019 in the department of respiratory medicine. The inclusion criteria were pulmonary MDR-TB diagnosed patients, more than 18 years, belonging to different sex, caste, literacy, occupation, economic status and place of living.

For the purpose of this study, 125 patients, that is, 20\% of the expected number of newly diagnosed cases in 2018 (614) were selected. Investigator visited Respiratory Medicine Department twice a week on Tuesday and Friday. On the days of visit, newly detected pulmonary MDR-TB patients admitted in the ward a day before, who met the study criteria and were willing to participate, were enrolled in the present study.

Ethical approval was obtained by the ethical committee of the institution PGIMS Rohtak, before the commencement of the study. An informed written consent was obtained from every patient selected for the study. Patients with psychiatric illness who were unable to cooperate and patients with serious illness or having co-morbidities like cardiac, hepatic, renal or nervous system disease were excluded from the study.

Data were collected by interview technique (Annexure 1) by administering pre-designed, pre-tested, semi structured schedule by the investigator himself. The data so collected were compiled, tabulated \& analysed applying suitable statistical tests (i.e., chi square test) using SPSS version 20.0 software.

\section{Operational Definition}

Patient level delay: Time between onset of symptoms till reaching at health facility or health provider. The delay was suspected if the time duration was more than consecutive 14 days in case of MDR suspect (symptomatic contact of diagnosed sputum +ve MDR-TB patient or treatment failure and defaulter cases).

\section{Result}

In the present study, out of 125 patients, 116 (92.8\%) had 
delay in consulting healthcare provider (govt. or private). The mean and median patient level delay was found to be 31.11 days and 21 days (Range 1-176 days).

The proportion of patient having delay in diagnosis was highest 43 (34.4\%) in age group of 31 to 40 year and among this age group 19 (44.2\%) had delay of 31 to 60 days. Overall maximum number of patients $51(40.8 \%)$ had patient level delay in diagnosis of 31 to 60 days.

Out of 76 male participants, 67 (88.15\%) had delay in seeking care for diagnosis of TB/ MDR-TB after appearance of symptoms. All 49 (100\%) females had some delay for seeking care regarding diagnosis of TB/ MDR-TB after appearance of symptoms.

Majority (58.4\%) of the patients were literate up to matriculation or above and among them, 30 (41.1\%) had delay of 15 to 30 days. Among the illiterates, 15 (60\%) patients had delay of 31 to 60 days (Shown in Table 1).

According to occupation, higher proportion (44.8\%) of patients were from labourer class and, in this class, majority $(62.5 \%)$ of patients had delay of more than 30 days. Similar pattern was found among housewives. Delay of 181 to 365 days was found only in farmer class. Two (2.5\%) patients from rural background were having delay of more than 180 days but it was not found to be statistically significant (Table 2).

Majority of the patients were addicted to either smoking or alcohol consumption or both and they were having delay of more than 30 days in seeking healthcare services. Patient level delay of more than 120 days was more among primary MDR-TB patients as compared to patients with past history of TB. More than three-fourth patients with past history of TB had 15 to 60 days delay when compared to primary MDR-TB patients, whereas, $40.7 \%$ patients had delay of more than 60 days. The proportional distribution of patients as per past history of TB was found to be statistically significant (Table 3).

Out of total 125 patients, 9 had no delay and, among the remaining, 116 patients had delay in diagnosis at the patient level. The reason for delay was: 41 (35.3\%) patients had delay in consulting healthcare due to lack of awareness of TB. Other reasons contributing to the patient delay were stigma and discrimination in society among 39 (33.6\%) while $36(31.1 \%)$ of patients had delay because of the ignorance of family members about the need to take patient to hospital (Table 4).

Table I.Extent of delay according to age, sex and education level of MDR-TB patients

\begin{tabular}{|c|c|c|c|c|c|c|c|c|c|}
\hline \multirow[b]{2}{*}{$\begin{array}{l}\text { Charac- } \\
\text { teristic }\end{array}$} & & \multicolumn{6}{|c|}{ Patient Level Delay } & \multirow[b]{2}{*}{$\begin{array}{c}\text { Total } \\
\text { n (100\%) }\end{array}$} & \\
\hline & & $\begin{array}{l}<14 \\
\text { Days } \\
\mathrm{n}(\%)\end{array}$ & $\begin{array}{c}15-30 \\
\text { Days } \\
\text { n (\%) }\end{array}$ & $\begin{array}{l}31-60 \\
\text { Days } \\
\text { n (\%) }\end{array}$ & $\begin{array}{c}61-120 \\
\text { Days } \\
\text { n (\%) }\end{array}$ & $\begin{array}{c}121-180 \\
\text { days } \\
\mathrm{n}(\%)\end{array}$ & $\begin{array}{c}\text { 181-365 } \\
\text { days } \\
\text { n (\%) }\end{array}$ & & \\
\hline \multirow{6}{*}{$\begin{array}{l}\text { Age } \\
\text { Groups }\end{array}$} & $<20$ & $0(0)$ & $5(55.6)$ & $1(11.1)$ & $0(0)$ & $3(33.3)$ & $0(0)$ & 9 & \multirow{6}{*}{$\begin{array}{c}x 2=68.389 \\
d f=25 \\
p=.001\end{array}$} \\
\hline & $21-30$ & $0(0)$ & $9(23.1)$ & $20(51.3)$ & $10(25.6)$ & $0(0)$ & $0(0)$ & 39 & \\
\hline & $31-40$ & $2(4.7)$ & $17(39.5)$ & $19(44.2)$ & $3(7)$ & $2(4.7)$ & $0(0)$ & 43 & \\
\hline & $41-50$ & $6(24)$ & $8(32)$ & $4(16)$ & $5(20)$ & $0(0)$ & $2(8)$ & 25 & \\
\hline & $51-60$ & $0(0)$ & $1(33.3)$ & $2(66.7)$ & $0(0)$ & $0(0)$ & $0(0)$ & 3 & \\
\hline & $>60$ & $1(16.7)$ & $0(0)$ & $5(83.3)$ & $0(0)$ & $0(0)$ & $0(0)$ & 6 & \\
\hline \multirow{2}{*}{ Sex } & Male & $9(11.8)$ & $24(31.6)$ & $33(43.4)$ & $8(10.5)$ & $0(0.0)$ & $2(2.6)$ & 76 (100) & \multirow{2}{*}{$\begin{array}{c}\chi 2=17.205 \\
d f=5 \\
p=.004\end{array}$} \\
\hline & Female & $0(0.0)$ & $24(31.6)$ & $18(36.7)$ & $10(20.4)$ & $5(10.2)$ & $0(0)$ & 49 (100) & \\
\hline \multirow{4}{*}{ Education } & Illiterate & $2(8)$ & $3(12)$ & $15(60)$ & $3(12)$ & $0(0)$ & $2(8)$ & 25 & \multirow{4}{*}{$\begin{array}{c}x 2=30.473 \\
d f=15 \\
p=.010\end{array}$} \\
\hline & $\begin{array}{c}\text { primary/ } \\
\text { middle }\end{array}$ & $5(18.5)$ & $7(25.9)$ & $12(44.4)$ & $3(11.1)$ & $0(0)$ & $0(0)$ & 27 & \\
\hline & $\begin{array}{c}\text { Matric/ } \\
10+2\end{array}$ & $2(3.4)$ & 23 (39.7) & $19(32.8)$ & $9(15.5)$ & $5(8.6)$ & $0(0)$ & 58 & \\
\hline & Graduate & $0(0)$ & $7(46.7)$ & $5(33.3)$ & $3(20)$ & $0(0)$ & $0(0)$ & 15 & \\
\hline \multicolumn{2}{|c|}{ Total } & $9(7.2)$ & $40(32)$ & $51(40.8)$ & $18(14.4)$ & $5(4)$ & $2(1.6)$ & 125 & \\
\hline
\end{tabular}


Table 2 Association of extent of delay in MDR-TB with Socio-demographic factors

\begin{tabular}{|c|c|c|c|c|c|c|c|c|c|}
\hline \multirow[b]{2}{*}{$\begin{array}{l}\text { Charac- } \\
\text { teristic }\end{array}$} & & \multicolumn{6}{|c|}{ Patient Level Delay } & \multirow[b]{2}{*}{$\begin{array}{c}\text { Total } \\
n \\
(100 \%)\end{array}$} & \\
\hline & & $\begin{array}{c}<14 \\
\text { Days } \\
\text { n (\%) }\end{array}$ & $\begin{array}{c}15-30 \\
\text { Days } \\
n(\%)\end{array}$ & $\begin{array}{c}31-60 \\
\text { Days } \\
\text { n (\%) }\end{array}$ & $\begin{array}{c}\text { 61-120 } \\
\text { Days } \\
\text { n (\%) }\end{array}$ & $\begin{array}{c}\text { 121-180 } \\
\text { days } \\
\text { n (\%) }\end{array}$ & $\begin{array}{c}\text { 181-365 } \\
\text { days } \\
\text { n (\%) }\end{array}$ & & \\
\hline \multirow{5}{*}{ Occupation } & Labor & $6(10.7)$ & $15(26.8)$ & $26(46.4)$ & $6(10.7)$ & $3(5.4)$ & $0(0)$ & 56 & \multirow{5}{*}{$\begin{array}{c}x 2=36.366 \\
d f=20 \\
p=.014\end{array}$} \\
\hline & Private Job & $1(5.9 \%)$ & $8(47.1)$ & $6(35.3)$ & $2(11.8)$ & $0(0)$ & $0(0)$ & 17 & \\
\hline & House Wife & $0(0)$ & $9(26.5)$ & $15(44.1)$ & $8(23.5)$ & $2(5.9)$ & $0(0)$ & 34 & \\
\hline & Student & $0(0)$ & $4(66.7)$ & $2(33.3)$ & $0(0)$ & $0(0)$ & $0(0)$ & 6 & \\
\hline & Farmer & $2(16.7)$ & $4(33.3)$ & $2(16.7)$ & $2(16.7)$ & $0(0)$ & $2(16.7)$ & 12 & \\
\hline \multirow{2}{*}{$\begin{array}{l}\text { Place of } \\
\text { Living }\end{array}$} & Rural & $6(7.6)$ & $25(31.6)$ & $32(40.5)$ & $12(15.2)$ & $2(2.5)$ & $2(2.5)$ & 79 & \multirow{2}{*}{$\begin{array}{c}x 2=2.474 \\
d f=5 \\
p=.780\end{array}$} \\
\hline & Urban & $3(6.5)$ & $15(32.6)$ & $19(41.3)$ & $6(13)$ & $3(6.5)$ & 0 & 46 & \\
\hline \multirow{2}{*}{ Distance } & $<10 \mathrm{Km} \mathrm{n} \mathrm{( \% )}$ & $7(6.3)$ & $37(33)$ & $47(42)$ & $16(14.3)$ & $3(2.7)$ & $2(1.8)$ & 112 & \multirow{2}{*}{$\begin{array}{c}x 2=7.012 \\
d f=5 \\
p=.220\end{array}$} \\
\hline & $>10 \mathrm{Km} \mathrm{n} \mathrm{( \% )}$ & $2(15.4)$ & $3(23.1)$ & $4(30.8)$ & $2(15.4)$ & $2(15.4)$ & $0(0)$ & 13 & \\
\hline \multicolumn{2}{|c|}{ Total } & $9(7.2)$ & $40(32)$ & $51(40.8)$ & $18(14.4)$ & $5(4)$ & $2(1.6)$ & 125 & \\
\hline
\end{tabular}

Table 3.Association of extent of delay in MDR-TB with Addiction and Past history of TB

$(n=125)$

\begin{tabular}{|c|c|c|c|c|c|c|c|c|c|}
\hline \multirow[b]{2}{*}{$\begin{array}{l}\text { Charac- } \\
\text { teristic }\end{array}$} & & \multicolumn{6}{|c|}{ Patient Level Delay } & \multirow[b]{2}{*}{$\begin{array}{c}\text { Total } \\
n \\
(100 \%)\end{array}$} & \\
\hline & & $\begin{array}{l}<14 \\
\text { Days } \\
\text { n (\%) }\end{array}$ & $\begin{array}{c}15-30 \\
\text { Days } \\
\text { n (\%) }\end{array}$ & \begin{tabular}{cc}
\multicolumn{2}{c}{$31-60$} \\
Days & $n$ \\
$(\%)$ &
\end{tabular} & $\begin{array}{c}\text { 61-120 } \\
\text { Days } \mathrm{n} \\
(\%)\end{array}$ & $\begin{array}{c}121-180 \\
\text { days } \\
n(\%)\end{array}$ & $\begin{array}{c}181-365 \\
\text { days } \\
n(\%)\end{array}$ & & \\
\hline \multirow{4}{*}{ Addiction } & Alcohol & $6(16.7)$ & $11(30.6)$ & $16(44.4)$ & $2(5.6)$ & $0(0)$ & $1(2.8)$ & 36 & \multirow{4}{*}{$\begin{array}{c}x 2=30.717 \\
d f=15 \\
p=.010\end{array}$} \\
\hline & Smoking & $0(0)$ & $3(27.3)$ & $3(27.3)$ & $5(45.5)$ & $0(0)$ & $0(0)$ & 11 & \\
\hline & Both & $3(12)$ & $7(28)$ & $12(48)$ & $2(8)$ & $0(0)$ & $1(4)$ & 25 & \\
\hline & None & $0(0)$ & $19(35.8)$ & $20(37.7)$ & $9(17)$ & $5(9.4)$ & $0(0)$ & 53 & \\
\hline \multirow{2}{*}{$\begin{array}{c}\text { Past } \\
\text { history of } \\
\text { TB } \\
\end{array}$} & Yes & $8(8.2)$ & 33 (33.7) & 43 (43.9) & $12(12.2)$ & $0(0)$ & $2(2)$ & 98 & \multirow{2}{*}{$\begin{array}{c}x 2=22.197 \\
d f=5 \\
p=.010\end{array}$} \\
\hline & No & $1(3.7)$ & 7 (25.9) & $8(29.6)$ & $6(22.2)$ & $5(18.5)$ & $0(0)$ & 27 & \\
\hline \multicolumn{2}{|c|}{ Total } & $9(7.2)$ & $40(32)$ & $51(40.8)$ & $18(14.4)$ & $5(4)$ & $2(1.6)$ & 125 & \\
\hline
\end{tabular}

Table 4.Reasons for patient delay in consulting healthcare provider

$(n=116)$

\begin{tabular}{|c|c|c|}
\hline Reasons & Frequency & Percent \\
\hline Lack of awareness about Disease & 41 & 35.3 \\
\hline Stigma and Discrimination & 39 & 33.6 \\
\hline Ignorance of Family member to take patient to hospital & 36 & 31.1 \\
\hline Total & 116 & 100 \\
\hline
\end{tabular}

\section{Discussion}

In present study, it was observed that overall $116(92.8 \%)$ MDR-TB patients had delay in consulting healthcare facility after being a suspected case of MDR-TB. The mean and median patient delay was found to be 31.11 days and 21 days, respectively.

The patient level delay considered in the present study was different from patient level delay considered in other 
studies. Few researchers have considered patient level delay from day one of appearing of symptoms. In a study by Li Y et al., mean delay was 38.5 days and median delay was 12.5 days, considering patient level delay from day one of appearing of symptoms. Taking the criteria of present study, mean delay in their study would be equivalent to 24.5 days. ${ }^{6}$ In this study by Li Y et al. delay was counted from the day of appearance of symptoms i.e. cough. In present study delay was counted after consecutive 14 days of appearance of symptoms of MDR-TB.

A few other studies have used the term diagnostic delay. These researchers had merged the patient level delay and peripheral level delay of the present study and considered it as diagnostic delay. The value of mean diagnostic delay in our study was 137 days. ${ }^{7}$ Narasimooloo R et. al., ${ }^{8}$ Zhang et al., ${ }^{9}$ were 9.78 days, 9 days, 12.4 weeks and 110 days, respectively.

In a study done by Rifat et al. in 207 MDR-TB patients, diagnostic delay (time from date of diagnostic sample provided to date of result and median delay) was 5 days. This was equivalent to tertiary care level delay in present study. This difference might be due to selection of the type of study subjects and the type of tertiary care health facilities. ${ }^{10}$

In present study, 41 (35.3\%) patients had delay in seeking healthcare due to lack of awareness of TB. Other reasons contributing to the patient delay were stigma and discrimination in 39 (33.6\%), family member ignorance to take the patient to healthcare facility in 36 (31.1\%). Extent of patient delay was significantly associated with socio-demographic factors like age, sex, literacy status, occupation, addiction, patients having past history of TB but not with caste, monthly family income, place of living, distance of home from nearest healthcare facility, treatment taken from private practitioners.

\section{Conclusion \& Recommendation}

Extent of patient delay was significantly associated with socio-demographic factors like age, sex, literacy status, occupation, addiction, patients having past history of TB but not with caste, monthly family income, place of living, distance of home from nearest healthcare facility, treatment taken from private practitioner. The mean and median patient delay was found to be 31.11 days and 21 days, respectively.

As per our findings, following interventions can be taken to decrease the extent of delay at patient level:

- There is urgent need to scale up the Information, Education and Communication (IEC) activities for the general public to increase the awareness regarding MDR-TB and to decrease the delay on the part of patients in consulting healthcare provider for diagnosis of MDR-TB at the earliest.

- This can be done by regular and repeated campaigns over mass media like Internet, local cable TV networks, newspapers, wall writing and hoardings about the identification of the disease. The contribution of the community with public health facilities and general public with private healthcare providers should also be highlighted for the initiatives taken regarding community participation in this regard.

\section{Conflict of Interest: None}

\section{References}

1. World Health Organization. Global TB Report 2019. World Health Organization. 2019; 1-277. Available from: https://apps.who.int/iris/bitstream/hand le/10665/329368/9789241565714-eng.pdf?ua=1.

2. Centre for disease control and prevention. TB Elimination (Multidrug-Resistant TB (MDR TB)). Atlanta. Centre for disease control and prevention. 2012; 1-2.

3. World Health Organization. Multidrug-Resistance TB (MDR-TB): 2017 Update. Geneva. World Health Organization; 2017. Available from: https://www.who. int/tb/challenges/mdr/MDR-RR_TB_factsheet_2017. pdf.

4. Alavi SM, Bakhtiyariniya P, Albagi A. Factors associated with delay in diagnosis and treatment of pulmonary tuberculosis. Jundishapur J Microbiol 2015; 8(3): 8-11. [PubMed/ Google Scholar].

5. Li Y, Ehiri J, Tang S, Li D, Bian Y, Lin H et al. Factors associated with patient, and diagnostic delays in Chinese TB patients: A systematic review and metaanalysis. BMC Med 2013; 11(1): Article number: 156. Available from: https://bmcmedicine.biomedcentral. com/articles/10.1186/1741-7015-11-156 [PubMed/ Google Scholar].

6. Li Y, Ehiri J, OrenE, HuD, Luo X, Liu Y etal. Are we doing enough to stem the tide of acquired MDR-TB in countries with high TB burden? Results of a mixed method study in chongqing, china. PLoS One 2014; 9(2): e88330. Available from: https://journals.plos. org/plosone/article?id=10.1371/journal. pone.0088330 [DOI: https://doi.org/10.1371/journal.pone.0088330/ PubMed/ Google Scholar].

7. Htun YM, Khaing TMM, Yin Y, Myint Z, Aung ST, Hlaing TM et al. Delay in diagnosis and treatment among adult multidrug resistant TB patients in Yangon Regional TB Center, Myanmar: A cross-sectional study. BMC Health Serv Res 2018; 18(1): 878. Available from: https://bmchealthservres.biomedcentral.com/ articles/10.1186/s12913-018-3715-4 [PubMed/ Google Scholar].

8. Narasimooloo R, Ross A. Delay in commencing treatment for MDR TB at a specialized TB treatment 
center in KwaZulu-Natal. S Afr Med J 2012; 102(6): 360-362. Available from: http://www.samj.org.za/ index.php/samj/article/view/5361/4127 [PubMed/ Google Scholar].

9. Zhang X, Yin J, Li H, Li S, Walley J, Zou G et al. Diagnostic and treatment delays of multidrug-resistant TB before initiating treatment: a cross-sectional study. Trop Med Int Heal 2015; 20(11): 1431-1437. Available from: https://onlinelibrary.wiley.com/doi/full/10.1111/ tmi.12566 [PubMed/ Google Scholar].

10. Rifat M, Hall J, Oldmeadow C, Husain A, Milton $\mathrm{AH}$. Health system delay in treatment of multidrug resistant TB patients in Bangladesh. BMC Infect Dis [Internet] 2015 [cited 2019 April 25]; 15(1): 526. Available from: https://bmcinfectdis.biomedcentral. com/articles/10.1186/s12879-015-1253-9 [PubMed/ Google Scholar]. 


\section{Annexure I}

\section{Questionnaire for finding out for Delay in Diagnosis of MDR TB Patients Attending Tertiary Care Hospitals in Haryana}

\section{B. Identification Data}

1. Name:

2. $\mathrm{S} / \mathrm{o} / \mathrm{D} / \mathrm{o} / \mathrm{W} / \mathrm{o}$ :

3. Age: $(1)<20$

(2) $21-30$

(3)31-40

(4) $41-50$

(5) $51-60$

(6) $>61$

4. Sex: (1) M

(2) F

5. Caste/ Religion: (1) General

(2) $O B C$

(3) SC

(4) Muslim

6. Family Income/ Month: (1)0-10

(2) $10-50$

(3) $>50$

7. Literacy: (1) Illiterate

(2) Primary/ Middle

(3) Matric/ 10+2

(4)graduate
(5) Postgraduate

8. Occupation: (1) Labour

(2) Govt. Employee

(3) Private. Job

(4)House Wife
(5) Student
(6) Farmer

9. Marital Status: (1) Married

(2) Unmarried

(3) Widow

(4) Divorce

10. Type of family: (1) Nuclear

(2) Joint

11. Address with Contact No.

12. Place of living: (1) Rural

(2) Urban

13. Residing under which: (1) PHC

(2) $\mathrm{CHC}$

(3) $\mathrm{DH}$

14. Distance of nearest health care facility from home: 1) $<10 \mathrm{~km}$

2) $>10 \mathrm{~km}$

B. Knowledge about Tuberculosis

15. Have you heard about TB? (1) Yes

(2) No

16. If yes have you heard of TB before your treatment started? (1) Yes

(2) No

17. What are signs and symptoms of TB? (1) Cough $>2 w k s$

(4) Weight Loss

(5) Hemoptysis

(6) Loss of Appetite

(3) Dyspnoea

18. Have you heard about MDR TB? (1) Yes

(2) No

19. Do you know difference between TB and MDR-TB? (1) Yes

(2) Evening rise of Temp

20. How does this disease spread? (1) Cough

(2) Touch (5)Clothes Sharing

21. Do you know MDR-TB patient spreads MDR-TB? (1) Yes

(2) No

22. What is the cause of TB? (1) Cough

(2) Smoking
(4) Virus
(5) Bacteria

23. What should be done when one is affected with TB? (1) Traditional Healer

(2) Doctor

(3) RMP
(4) Home Remedies

24. What you know about severity of TB? (1)Highly Infectious
(3) can be cured
(4) don't Know

25. How much you trust this treatment being given to you: (1) Fully

(2) Can cause Death

26. Do you know how it is diagnosed?

(1) Sputum Examination

(2) Partial

(3) Don't Know
(3) Blood Examination
(4) Don't Know

(2) X-Ray

(7) Night Sweats

(2) No

(3) Smoking (4) Eating Together

(3) Religious 
27. Do you know about CB-NAAT test? (1) Yes

(2) No

28. Source of the information: (1) Family Member
(4) Newspaper
(5) Tv/ Radio

(2) Friend

(3) Health Worker

\section{History of Mdr-Tb and Related Illness}

29. History of contact with other known cases of TB? (1) Yes

(2) No

30. Have you come across any case of known MDR-TB patient? (1) Yes

(2) No

31. Have you infected with TB previously also: (1) Yes

(2) No

32. If yes, when did you have the symptoms of TB for the first time? (1) <1yr back
(3) 2-5yrs
(4) $>5 y r s$
(5) NA

33. Have you taken treatment for TB before? (1) Yes

(2) No

(3) NA

34. Have you completed the full course of treatment:

(1) Yes

(2) No

(3) NA

35. If NO, what was reason of not completing treatment?
(1) Felt disease was cured?
(2) hanged to Ayurvedic/ Other Medicine
(3) You changed your residence
(4) Shortage of drugs at centre
(5) Side effects were more
(6) Any other
(7) NA

36. History of intake of: (1) Smoking

(2) Alcohol

(3)Both

(4) None

37. Do you know your HIV status: (1) +vet

(2) -vet

(3) Don't Know

38. Do you have Diabetes? (1) Yes

(2) No

39. Do you have some other illness/Mental Illness: (1) Yes

(2) No

40. Do you have any history of seizures? (1) Yes

(2) No

\section{Patient Level Delay}

41. When you developed symptoms of MDR-TB for this time?

42. Did you take any treatment at home personally? (1) Yes

(2) No

43. Where did you consult for the symptoms of TB this time? (1) Government
(2). Pvt. Medical shops
(3) Traditional
(4) Other

44. How long you took treatment for the symptoms of TB this time? (1) <2wks
(3) 1 Month
(4) 2 Months
(5) 3 Months
(6) 4 Months
(7) 5 Months
(8) 6 Months
(9) 7 Months
(10) 8 Months
(11) 9 Months
(12) 10 Months
(13) 11 Months
(14) 12 Months

(2) $>2$ wks

45. What were the reasons of delay in seeking health care facility?
(1) Lack of awareness about Disease
(2) Stigma and Discrimination
(3) Ignorance of Family member to take patient to hospital 